\title{
Simultaneous Production of Synthetic Gas and Metal-Biochar through Co-Pyrolysis of Zirconia and Coffee Waste
}

\author{
DONG-WAN $\mathrm{CHO}^{1}$
}

\author{
${ }^{1}$ Geological Environment Division, Korea Institute of \\ Geoscience and Mineral Resources, Gwahak-ro 124, \\ Yuseong-gu, Daejeon, 34132, Republic of Korea \& \\ dwcho@kigam.re.kr
}

The $\mathrm{CO}_{2}$ pyrolysis of $\mathrm{CW}$ presented the high level of $\mathrm{CO}$ production (14.3 mole\%) during two stages of non-isothermal ( 280 to $700{ }^{\circ} \mathrm{C}$ ) and isothermal pyrolysis (kept at $700{ }^{\circ} \mathrm{C}$ ). At the same condition, the incorporation of $\mathrm{ZrO}_{2}$ improved the $\mathrm{CO}$ generation up to about twice that of $\mathrm{CW}(29.5 \mathrm{~mole} \%)$ by possibly inducing more conversion of pyrolytic oil into gas. The characterization results exhibited that $(\mathrm{ZrB})$ possessed the distinctive surface morphology that highly graphitic- and porous carbon layers were covered by $\mathrm{ZrO}_{2}$ nanoparticle clusters. In a series of adsorption experiments, $\mathrm{ZrB}$ composite showed $\mathrm{pH}$-dependent $\mathrm{As}(\mathrm{V})$ adsorption and $\mathrm{pH}$ neutralization ability. The adsorption proceeded relatively rapid with $95 \%$ removal during $120 \mathrm{~min}$ in the early stage, followed by $5 \%$ removal in the remaining $240 \mathrm{~min}$. The maximum adsorption capacity was found to be $25.2 \mathrm{mg} \mathrm{g}^{-1}$ at final $\mathrm{pH}$ 8. The reusability and stability of $\mathrm{ZrB}$ were demonstrated in the 6 consecutive cycles of adsorption/desorption. As a result, $\mathrm{ZrO}_{2}$-assisted $\mathrm{CO}_{2}$ pyrolysis can potentially produce fuel gas with high $\mathrm{CO}$ fraction and composite adsorbent suitable for $\mathrm{As}(\mathrm{V})$ removal in acidic wastewater. 